\title{
Application of acrylic-based coatings for concrete protection
}

\author{
Aleksander Kozak ${ }^{1, *}$ \\ ${ }^{1}$ Cracow University of Technology, Warszawska Street 24, Cracow, 31-155, Poland
}

\begin{abstract}
The paper presents a description of acrylic-based polymers used in civil engineering for concrete protection. Some information on chemistry and properties of the acrylic coatings is included together with current trends in coating technology. Moreover, the paper shows test results, that is barrier properties and SEM observations of a commercial elastic acrylic-based polymer subject to artificial weathering for $1000 \mathrm{~h}$. The studies showed that the weathering did not change carbon dioxide permeability of the tested coating and its influence on water vapour permeability of the material was also very small. The test results show that an assessment of coating performance based only on barrier properties is not enough.
\end{abstract}

\section{Introduction}

In the middle of XX century the first acrylic water-borne emulsions were developed. Later on, a wide range of modifications have been made in order to produce durable coatings. Comonomers like styrene are commonly used to ensure appropriate hardness, gloss, and high water absorption resistance. Further modifications include addition of monomers containing functional groups like carbonyl or hydroxyl. The obtained polymers can be used to produce two-component coatings containing water-borne acrylic and a crosslinking material used as a hardener. Moreover, single-component and self-crosslinking systems are also used. They set by air oxidation [1]. Water-borne acrylic coatings are known for some sought-after properties, such as very good weathering resistance and toughness, thus these types of coatings find a wide range of applications in civil engineering. In addition, they are a very good alternative for solvent-born systems keeping in mind safety of workers and environment protection. Current tendency is to significantly reduce volatile organic content (VOC) in coating, and the acrylic coating follows the trend very well. The VOCs are present in the acrylics but in very small amounts. They play a very important role in formation of film. During the process, fusion of the polymer particles occurs in the liquid coating, and, initially, the channels among the latex particles are formed which later on disappear when the particles merge together. In order to accelerate the process, coalescing agents are added. These volatile solvents optimize the coalescence of the particles. For any polymers exists a limiting temperature above which full coalescence is possible. This temperature is called minimum film-formation temperature (MFFT). If a dispersion paint

\footnotetext{
${ }^{*}$ Corresponding author: akozak@pk.edu.pl
} 
film dries below the MFFT of its polymer, the film will be quite brittle, and the formation of a coherent film will be impossible. By adding a coalescing agent the temperature can be reduced enabling full coalescence. The most effective coalescing agents are partially watersoluble coalescing agents $[1,2]$.

One of the more important additions to coatings is titanium dioxide, which ensures gloss and chalk resistance. Moreover, nano- $\mathrm{TiO}_{2}$ has catalytic properties which are very useful in removing impurities [3]. Acrylic coatings exhibit good adherence to concrete substrate and, also, show good alkali resistance, albeit to mild ones. It is recommended to apply an acrylic coating on fresh concrete when it is at least one month old to achieve very good long-term performance properties. Moreover, this type of coating ensures good balance between water vapour permeability and carbon dioxide resistance. The barrier properties are often expressed in a diffusion equivalent air layer thickness $S_{d}[\mathrm{~m}]$. In the case of $\mathrm{S}_{\mathrm{d}}$ for $\mathrm{CO}_{2}$, the value should be more than 50 meters, whereas $\mathrm{S}_{\mathrm{d}}$ for $\mathrm{H}_{2} \mathrm{O}$ ought to be less than 2 meters $[4,5]$. Another very beneficial feature of acrylic coatings is their high weathering resistance, thus they are often chosen as protective materials on concrete structures. All above features are very desired while choosing appropriate coatings for longterm concrete protection [4,6-9].

The paper presents test results of barrier properties of a highly elastic acrylic coating subject to artificial weathering for $1000 \mathrm{~h}$. Moreover, some SEM observations of the material have also been made.

\section{Materials and methods}

The elastic acrylic-based coating was tested for $1000 \mathrm{~h}$, i.e. 126 cycles in a weathering chamber according to ASTM G 154a [10]. The tested coating was either applied onto concrete substrate or studied in the form of foils. One weathering cycle consisted of irradiating with the use of UV lamps at $60 \pm 3^{\circ} \mathrm{C}$ for $6 \mathrm{~h}$ and, then, sprinkling with distilled water at $40 \pm 3^{\circ} \mathrm{C}$ for $2 \mathrm{~h}$. The weathering cycles started with the UV irradiation, as proposed by Aragon and Frizzi [11]. The radiation ranged from $295 \mathrm{~nm}$ to $400 \mathrm{~nm}$, which corresponded to UVA+B. The radiation intensity was $40 \pm 2 \mathrm{~W} / \mathrm{m}^{2}$ (measured with a Solarmeter) and was of the same value as the one recorded on a very sunny summer day in Cracow. The studies focused on barrier properties of the material and some SEM observations, whereas mechanical properties (adherence to concrete substrate and elongation tests) together with a structural analysis (FTIR) of the material were described in [12]. The permeability to carbon dioxide before and after weathering was determined using the RILEM-Cembureau method [13], which was described in detail in [14]. Cylindrical concrete samples $150 \mathrm{~mm}$ in diameter and $50 \mathrm{~mm}$ thick were used in all tests. Before the tests, they were earlier cut from $150 \mathrm{~mm} \times 300 \mathrm{~mm}$ cylinders (Fig.1). Prior to the tests, the coatings were applied onto the concrete substrates and seasoned for a period given in the data sheet of the material. 


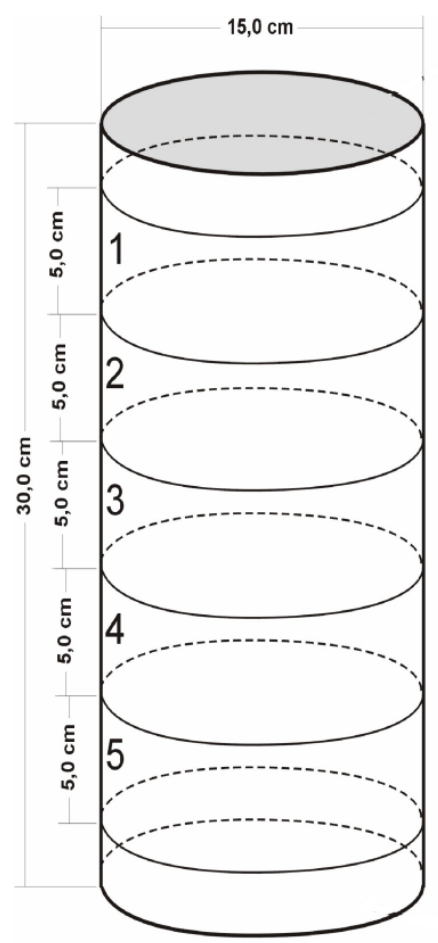

Fig. 1. Concrete cylinder for preparing samples for $\mathrm{CO}_{2}$ permeability tests.

Water vapour permeability was determined using coatings in the form of foils. The tests were done according to ASTM E-96 [15].

\section{Results and discussion}

\subsection{Carbon dioxide permeability}

The test results of both initial and weathered samples showed that the coating was completely impermeable to carbon dioxide under the test conditions and fulfilled the requirements concerning $S_{d}$ for $\mathrm{CO}_{2}[4,5]$.

\subsection{Water vapour permeability}

The permeability to water vapour was determined, and the equivalent air layer thickness $S_{d}$ for $\mathrm{H}_{2} \mathrm{O}$ was calculated. Table 1 shows water vapour permeability of the coating foils.

Table 1. Water vapour permeability.

\begin{tabular}{|c|c|c|c|c|c|c|}
\hline $\begin{array}{c}\text { Aging } \\
\text { time }\end{array}$ & $\begin{array}{c}\text { Sample } \\
\text { no. }\end{array}$ & $\begin{array}{c}\Delta \text { m under } \\
\text { steady } \\
\text { state }\end{array}$ & $\mathrm{H}_{2} \mathrm{O}$ flux & $\begin{array}{c}\text { Diffusion } \\
\text { coefficient }\end{array}$ & $\begin{array}{c}\text { Diffusion } \\
\text { resistance }\end{array}$ & $S_{d}$ \\
\hline & & {$[\mathrm{g}]$} & {$\left[\mathrm{kg} / \mathrm{m}^{2} \mathrm{~s}\right]$} & {$\left[\mathrm{m}^{2} / \mathrm{s}\right]$} & {$[\mathrm{s} / \mathrm{m}]$} & {$[\mathrm{m}]$} \\
\hline
\end{tabular}




\begin{tabular}{|c|c|c|c|c|c|c|}
\hline 1 & 2 & 3 & 4 & 5 & 6 & 7 \\
\hline \multirow{3}{*}{$\begin{array}{c}0 \\
\text { cycles }\end{array}$} & 1 & 0.180 & $6.94 \mathrm{E}-07$ & $9.98 \mathrm{E}-09$ & 23042 & 0.65 \\
\hline & 2 & 0.174 & $6.71 \mathrm{E}-07$ & $9.65 \mathrm{E}-09$ & 23837 & 0.67 \\
\hline & 3 & 0.186 & $7.18 \mathrm{E}-07$ & $1.03 \mathrm{E}-08$ & 22299 & 0.63 \\
\hline \multicolumn{6}{|r|}{ mean } & 0.65 \\
\hline \multirow{3}{*}{$\begin{array}{c}126 \\
\text { cycles }\end{array}$} & 1 & 0.058 & 2.24E-07 & $3.22 \mathrm{E}-09$ & 70299 & 2.02 \\
\hline & 2 & 0.059 & $2.28 \mathrm{E}-07$ & $3.27 \mathrm{E}-09$ & 61905 & 1.98 \\
\hline & 3 & 0.067 & $2.58 \mathrm{E}-07$ & 3.72E-09 & 76808 & 1.75 \\
\hline \multicolumn{6}{|r|}{ mean } & 1.92 \\
\hline
\end{tabular}

The study showed that the acrylic coating before weathering had the mean $\mathrm{S}_{\mathrm{d}}$ for $\mathrm{H}_{2} \mathrm{O}$ value 0.65 , thus the material fulfilled the requirements [4,5]. A slight increase in $S_{d}$ value was noted after 126 cycles of weathering, but the samples still fulfilled appropriate requirements. Such changes could be explained by further curing of the polymer while aging. It appears that assessing coating behaviour while weathering based only on barrier properties does not show the actual condition of the material. As given in [12], after 126 weathering cycles the coating showed significant changes in deformation and strength.

\subsection{SEM observations}

The use of a Zeiss EVO MA 10 microscope allowed observing changes in the coating surface after weathering. Fig.2 and Fig.3 show coatings before and after weathering for $1000 \mathrm{~h}$, respectively. SEM pictures showed that after aging some destruction processes have taken place in the coating.

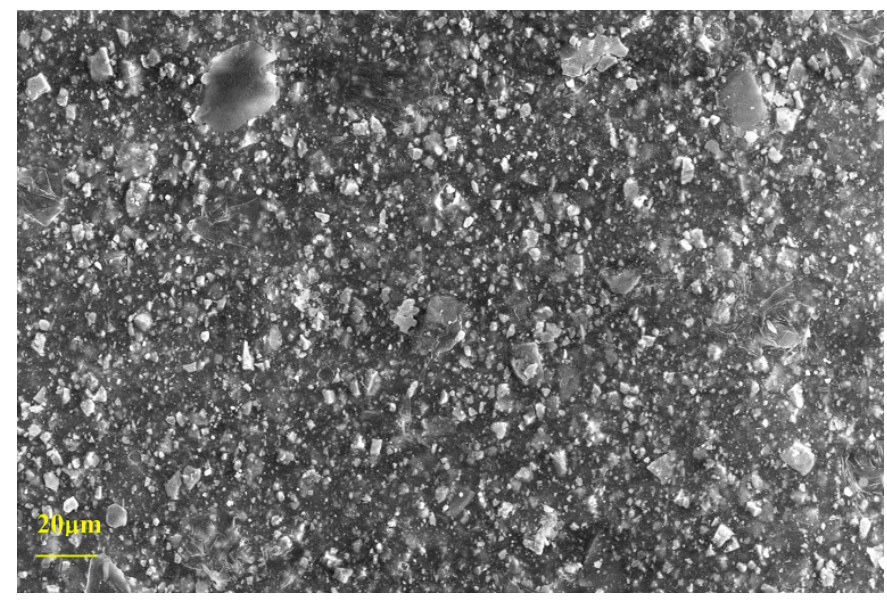

Fig. 2. SEM picture before weathering. 


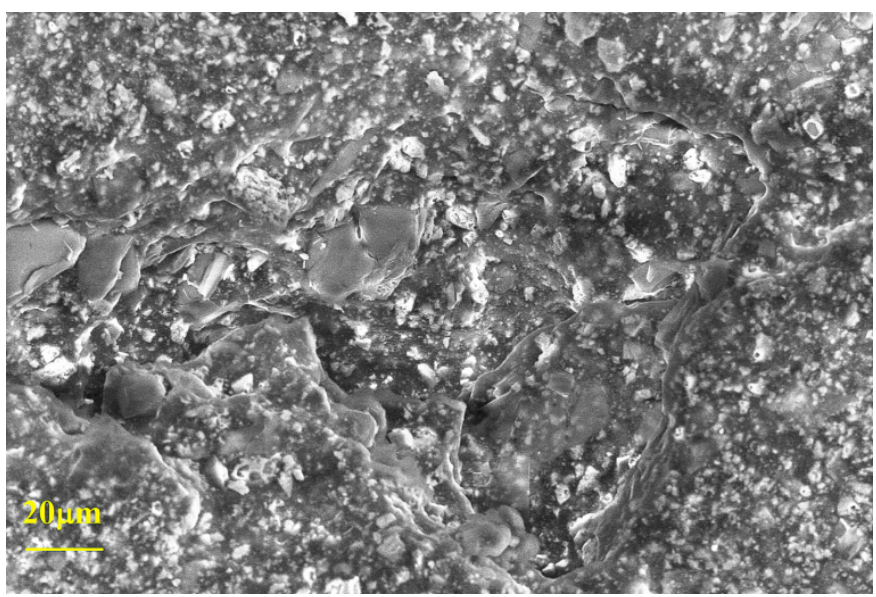

Fig. 3. SEM picture after weathering.

\section{Conclusions}

Based on the obtained test results, the following conclusions can be drawn:

1. The studies showed that the artificial weathering carried out according to the proposed research programme did not change resistance to carbon dioxide permeability. The samples were completely impermeable to carbon dioxide before and after accelerated weathering. 2. Water vapour permeability tests showed a slight increase in $\mathrm{S}_{\mathrm{d}}$ for $\mathrm{H}_{2} \mathrm{O}$ after artificial weathering, but the value still fulfilled the requirements. It seems it could be due to additional curing of the material while weathering.

3. Scanning electron microscopy showed some degradation in the coating after 126 cycles. 4. Assessing coating performance based only on the examination of its barrier properties is not enough to determine the actual performance of the material.

\section{References}

1. L.M. Smith, Generic coating types. An introduction to industrial maintenance coating materials. (TPC Books, 1996)

2. https://coatings.specialchem.com/selection-guide/coalescing-agents-in-coatings (January, 2018)

3. E. Stanaszek-Tomal, A. Kozak., Energy efficient, sustainable building materials and products (Ed. by I. Hager, Cracow, 2017)

4. R. Bassi, S.K. Roy, Handbook of coatings for concrete (Whittles Publishing, 2002)

5. T. Zafeiropoulou, E. Rakanta, G. Batis, Prog. in Org. Coat. 72 (2011)

6. N.L. Thomas, Prog. in Org. Coat. 19 (2) (1991)

7. P.C. Harwood, Surface coatings - specification criteria. Protection of concrete: Proceedings of the international conference, 176-184 (1990)

8. R.N. Swamy, S. Takinawa, Surface coatings to preserve concrete durability. Protection of Concrete: Proceedings of the international conference, 129-144 (1990)

9. O. O. Knudsen, A. Forsgren, Corrosion control through organic coatings. $2^{\text {nd }}$ edition (CRC Press, 2017)

10. ASTM G154a (2000)

11. M.A. Aragon, E. Frizzi, Prot. Coat. Europe, 8-14 (2002)

12. A. Kozak, Przem. Chem. 94(8), 1348-1350 (2015) 
13. RILEM Technical Recommendation: Tests for gas permeability of concrete TC (1999)

14. A. Kozak, Proced. Eng. 108, 664-672 (2015)

15. ASTM E-96 (2000) 